\title{
Chapter 12 \\ Developments in Ground Motion Predictive Models and Accelerometric Data Archiving in the Broader European Region
}

\author{
Sinan Akkar and Özkan Kale
}

\begin{abstract}
This paper summarizes the evolution of major strong-motion databases and ground-motion prediction equations (GMPEs) for shallow active crustal regions (SACRs) in Europe and surrounding regions. It concludes with some case studies to show the sensitivity of hazard results at different seismicity levels and exceedance rates for local (developed from country-specific databases) and global (based on databases of multiple countries) GMPEs of the same region. The case studies are enriched by considering other global GMPEs of SACRs that are recently developed in the USA. The hazard estimates computed from local and global GMPEs from the broader Europe as well as those obtained from global GMPEs developed in the US differ. These differences are generally significant and their variation depends on the annual exceedance rate and seismicity. Current efforts to improve the accelerometric data archives in the broader Europe as well as more refined GMPEs that will be developed from these databases would help the researchers to understand the above mentioned differences in seismic hazard.
\end{abstract}

\subsection{Introduction}

The development of ground-motion prediction equations (GMPEs) for shallow active crustal regions in Europe has initiated with the efforts of Ambraseys (1975), approximately a decade after the first ground-motion model proposed by

\footnotetext{
S. Akkar $(\bowtie)$

Kandilli Observatory and Earthquake Research Institute, Boğaziçi University,

İstanbul 34684, Turkey

e-mail: sinan.akkar@boun.edu.tr

Ö. Kale, $\mathrm{PhD}$

Department of Civil Engineering, Middle East Technical University, Ankara 06800, Turkey

e-mail: ozkankale@gmail.com
}

A. Ansal (ed.), Perspectives on European Earthquake Engineering and Seismology, Geotechnical, Geological and Earthquake Engineering 39,

DOI 10.1007/978-3-319-16964-4_12 
Esteva and Rosenblueth (1964). ${ }^{1}$ In the past 40 years, well over 100 GMPEs are developed in Europe and neighboring countries for estimating the future groundmotion levels in terms of elastic spectral ordinates and peak ground acceleration, PGA (Douglas 2011). ${ }^{2}$ Most of these GMPEs are tailored from datasets specific to a region or country but there are also ground-motion models developed by combining strong motions of many countries in the broader Europe. ${ }^{3}$ As everywhere else in the world, the quality and quantity of GMPEs in Europe are directly related to the availability of observational datasets. Their level of complexity to explain the physical process of earthquakes has also direct connection with the strong-motion data collection efforts under international or national programs.

As indicated above, there are three common practices in Europe for developing GMPEs. The first approach focuses on the regional datasets to estimate ground motions (e.g., Massa et al. 2008; Bragato and Slejko 2005). The second approach uses country-based datasets (e.g., Akkar and Çağnan 2010; Bindi et al. 2011), whereas the third group of model developers combines data from different countries in and around Europe (e.g., Ambraseys et al. 2005). (In some cases supplementary strongmotion data from USA or Japan are also used by the third group modelers). Researchers from the first two groups aim to capture the region-specific source, path and site effects on the ground-motion amplitudes estimates without contaminating the indigenous data from other regions. The GMPEs developed from regional and country-based datasets are generically called as local GMPEs. Researchers following the last approach accentuate that recordings from countries that are located in similar tectonic regimes are expected to exhibit similar features. This assumption generally yields larger ground-motion datasets with better distribution, for example in magnitude-distance space, with respect to regional or country-based datasets. Therefore, the regressed functional forms of the third group models are generally better constrained in terms of main estimator parameters. However, possible data contamination, for example due to regional attenuation differences, may provoke speculations on their efficient use in some hazard studies. As the third group ground-motion models are developed from datasets of multiple countries, they are called as global GMPEs. Their datasets are also referred to as global databases.

Different perspectives in the above approaches raise questions about the existence of regional dependence among the European GMPEs with emphasis on the epistemic and aleatory uncertainties. The aleatory uncertainty (measured with the standard deviation, sigma, of GMPE) that is generally referred to as intrinsic variability of

\footnotetext{
${ }^{1}$ Predictive model by Esteva and Rosenblueth (1964) was proposed for the Western USA whereas the Ambraseys (1975) GMPE was developed for Europe.

${ }^{2}$ There are other ground-motion equations estimating peak ground velocity (e.g., Akkar and Bommer 2007; Tromans and Bommer 2002) and ground-motion intensity measures such as vertical-to-horizontal spectral ratios (e.g., Akkar et al. 2014b; Bommer et al. 2011) for Europe and surrounding regions. These predictive models are not considered in this article.

${ }^{3}$ Datasets compiled from different European and neighboring countries are generally referred to as pan-European datasets (Bommer et al. 2010). The GMPEs developed from these datasets are called as pan-European GMPEs.
} 
Fig. 12.1 Comparisons between the standard deviations of local and pan-European (global) predictive models that estimate PGA

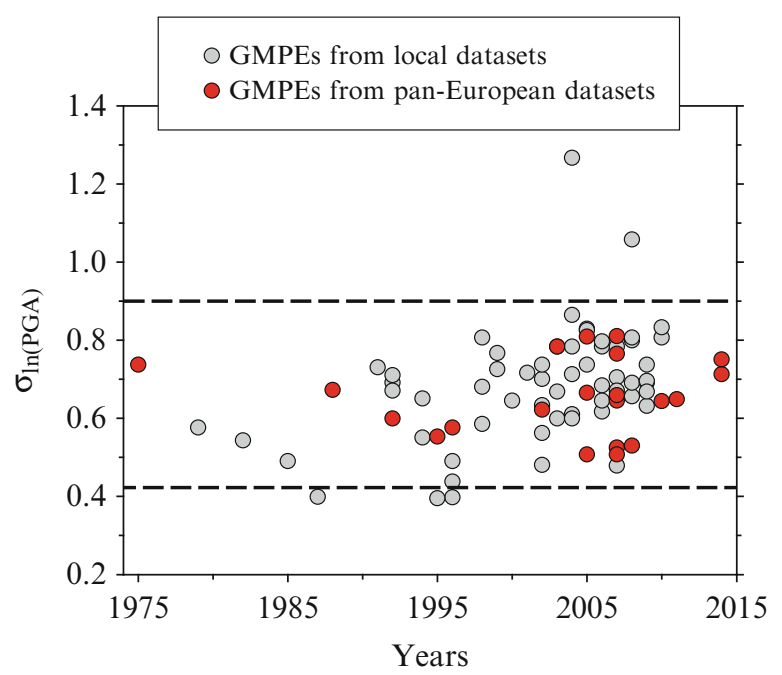

ground motions may also reflect the uncertainties stemming from dataset quality and its composition (e.g., local vs. global databases), modeling of GMPE and regression technique used in fitting (Strasser et al. 2009). For example, GMPEs for PGA that are developed from local or pan-European (global) datasets do not show a clear difference in sigma distribution as given in Fig. 12.1. Thus, the better constrained pan-European GMPEs do not possess lesser aleatory variability with respect to their local counterparts. The converse of this argument is also defendable: local GMPEs do not show reduced aleatory variability to speculate lesser contamination in their data.

Figure 12.2 compares the period-dependent sigma trends between NGA-West $1^{4}$ (Power et al. 2008), NGA-West $2^{4}$ (Bozorgnia et al. 2014) and the most recent pan-European GMPEs (Akkar et al. 2014c; Bindi et al. 2014; Akkar and Bommer 2010; Ambraseys et al. 2005). NGA-West1 and NGA-West2 GMPEs use wide spread shallow active crustal ground motions mainly from California, Taiwan (NGA-West1) and additionally from Japan, China and New Zealand (NGA-West2). They are also referred to as global GMPEs. The comparisons in Fig. 12.2 are done for $M_{w} 5$ and $M_{w} 7$ and the shaded areas in each panel represent the upper and lower sigma bounds of the chosen pan-European equations. The NGA-West1 and NGA-West2 GMPEs tend to yield lower sigma with respect to pan-European GMPEs. Note that the NGA-West2 predictive models are developed to bring improvements over NGA-West1 GMPEs in terms of additional data, explanatory variables and extended magnitude and distance ranges but their sigma values are larger with respect to their predecessors. The larger standard deviations in NGA-West2 GMPEs can be the manifestations of aggregated

\footnotetext{
${ }^{4}$ NGA-West1 and NGA-West2 are two projects to develop shallow active crustal GMPEs for seismic hazard assessment in the Western US. NGA-West2 project is the successor of NGA-West1.
} 



Fig. 12.2 Comparisons of sigma between NGA-West1 (Abrahamson and Silva (2008) - AS08, Boore and Atkinson (2008) - BA08, Campbell and Bozorgnia (2008) - CB08, Chiou and Youngs (2008) - CY08), NGA-West2 (Abrahamson et al. (2014) - ASK14, Boore et al. (2014) - BSSA14, Campbell and Bozorgnia (2014) - CB14, Chiou and Youngs (2014) - CY14) and some representative pan-European GMPEs (Akkar et al. 2014c; Bindi et al. 2014; Akkar and Bommer 2010; Ambraseys et al. 2005). The gray shaded areas show the upper and lower sigma bounds of pan-European GMPEs. The blue and red lines refer to period-dependent sigma variations of NGA-West1 and NGA-West2 predictive models, respectively. Comparisons are done for a rock site $\left(\mathrm{V}_{\mathrm{S} 30}=760 \mathrm{~m} / \mathrm{s}\right)$ located $10 \mathrm{~km}$ away from a $90^{\circ}$ dipping strike-slip fault. The selected magnitudes for comparisons are $\mathrm{M}_{\mathrm{w}} 5$ (left panel) and $\mathrm{M}_{\mathrm{w}} 7$ (right panel)

uncertainty due to new data and additional explanatory variables. Interestingly, the core accelerometric data sources of NGA-West 1 and NGA-West2 GMPEs do not include large numbers of ground motions from Europe that can, speculatively, be a factor for the observed differences in the sigma variation between NGA and pan-European GMPEs.

The above observations suggest that further systematic studies are required to understand the sources of differences or similarities in the aleatory variability between local and pan-European GMPEs. Such studies should also be performed between European and other well constrained global ground-motion models that are developed outside of Europe. An extensive summary about the factors controlling sigma and worldwide studies to reduce sigma can be found in Strasser et al. (2009).

Douglas $(2004,2007)$ indicated that there is no strong evidence confirming regional dependence for the GMPEs produced in the broader European region since the empirical observations are still limited. He also emphasized that the level of complexity in the current pan-European GMPEs is insufficient for a clear understanding about the contribution of epistemic uncertainty on the median ground-motion estimates (Douglas 2010). However, complexity in ground-motion models does not necessarily imply a better identification of epistemic uncertainty as complex GMPEs contain superior numbers of estimator parameters that may lead to overfit to empirical observations (Kaklamanos and Baise 2011). Bommer et al. (2010) showed that GMPEs developed from pan-European datasets and ground-motion models derived from NGA-West1 GMPEs would yield similar ground-motion estimates for moderate-to-large magnitude earthquakes. These authors indicated that the regional differences in ground-motion estimates would 
be prominent towards smaller magnitude earthquakes, which is a parallel observation with the studies conducted in the other parts of the world (Chiou et al. 2010; Atkinson and Morrison 2009). On the other hand, Scasserra et al. (2009) emphasized that the use of NGA-West1 GMPEs may over predict the hazard in Italy at large distances because Italian data attenuate faster than the trends depicted in NGA-West1 GMPEs. In a separate study, Akkar and Çağnan (2010) who developed a GMPE from an extended Turkish database showed that NGA-West1 GMPEs and ground-motion predictive models from pan-European datasets would yield conservative estimates with respect to their GMPE for different earthquake scenarios at different spectral ordinates. Recently, Kale et al. (2015) showed the existence of distance and magnitude dependent differences between the Iranian and Turkish shallow active crustal ground-motion amplitudes. Yenier and Atkinson (2014) found evidence on the regional dependence of large magnitude earthquakes in New Zealand and western North America. Almost all NGA-West2 GMPEs consider regional differences in their ground-motion estimates (Gregor et al. 2014).

Understanding the driving factors behind the observations highlighted in the above paragraphs requires detailed studies that consider different aspects of several topics related to database quality, GMPEs and their interdependencies. This paper does not intend to conduct such a study but aims at a comprehensive discussion about the current state of accelerometric databases and GMPEs for SACRs in the broader Europe. We believe that this information would provide a strong ground for the aforementioned detailed studies to scrutinize the existence of regional differences within broader Europe for shallow active crustal earthquakes. The paper ends by presenting the results of some probabilistic seismic hazard studies (PSHA) to evaluate the level of differences in the estimated hazard upon the use of most recent local and global European GMPEs as well as those developed in NGA-West1 and NGA-West 2 projects. The comparative PSHA results essentially emphasize the impact of using current local and global GMPEs to the estimated ground motions in terms of annual exceedance rates and seismicity level.

\subsection{Evolution of Major Strong-Motion Databases in the Broader Europe}

Strong-motion data collection in Europe started in the beginning of 1970s in Imperial College under the leadership of Prof. Ambraseys (deceased in 2012). It is continued progressively through multi-national collaborations (Ambraseys 1990; Ambraseys and Bommer 1990, 1991) and a CD-ROM of 1,068 tri-axial accelerometric data was released in 2000 as a solid product of this effort (Ambraseys et al. 2000). The data in the CD-ROM were expanded to a total of 2,213 accelerograms from 856 earthquakes recorded at 691 strong-motion stations (Ambraseys et al. 2004a) and it is disseminated through the Internet Site for European Strong-Motion Data (ISESD) web page (http://www.isesd.hi.is). 
a

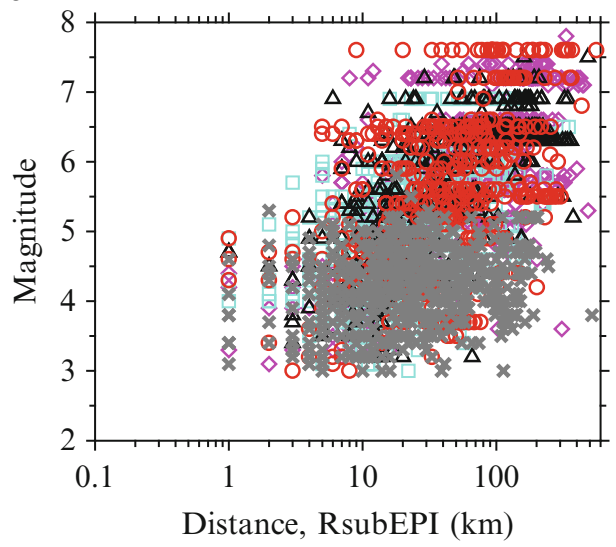

b

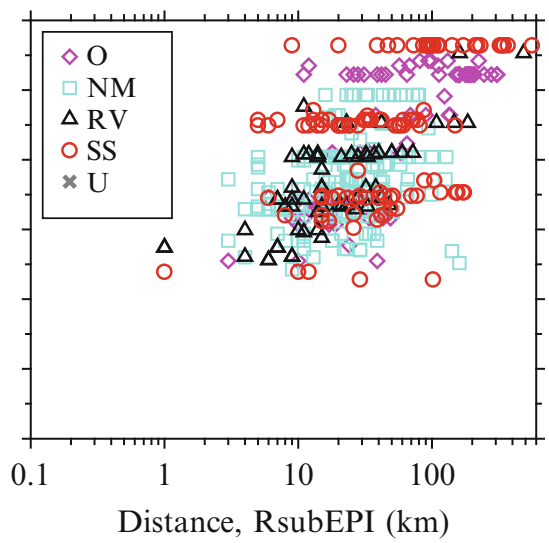

Fig. 12.3 Magnitude vs. distance scatters of (a) ISESD, (b) ESMD. Different symbols with different color codes show the distribution of fault mechanisms in these databases ( $O$ odd, $N M$ normal, $R V$ reverse, $S S$ strike-slip, $U$ unknown). Almost $50 \%$ of the data in ISESD and ESMD are collected from Italy, Greece and Turkey. These countries are followed by Iran (11\% of the whole data)

Figure 12.3a shows the magnitude vs. distance scatter of ISESD strong-motion database. It spans accelerograms from broader Europe between 1976 and 2004. The earthquake metadata (e.g., geometry, style-of-faulting, magnitude estimations etc.) in ISESD was extracted either from specific earthquake studies (institutional reports and papers published in peer-reviewed journals) or ISC bulletin (International Seismological Center, www.isc.ac.uk). The earthquake location information was taken from local or national seismic networks whenever they were assessed as more reliable than the international networks. The strong-motion station information (site conditions, station coordinates, shelter type) was obtained from the network owners. The soil classification of strong-motion sites in ISESD relies on $\mathrm{V}_{\mathrm{S} 30}$ (average shear-wave velocity in the upper $30 \mathrm{~m}$ soil profile). However, the $\mathrm{V}_{\mathrm{S} 30}$ data were mostly inferred from geological observations in ISESD as the measured shear-wave velocity profiles were typically unavailable by the time when it was assembled. The processed strong-motion records in ISESD were band-pass filtered using an elliptical filter with constant high-pass and low-pass filter cut-off frequencies $(0.25$ and $25 \mathrm{~Hz}$, respectively). After the release of ISESD, a small subset of this database was re-processed using the phaseless (acausal) Butterworth filter with filter cut-off frequencies adjusted individually for each accelerogram. The individual filter cut-off frequencies were determined from the signal-to-noise ratio of each accelerogram. This subset was published as another CD-ROM that is referred to as European Strong-Motion Data (ESMD; Ambraseys et al. 2004b). The extent of ESMD in terms of magnitude and distance is given in Fig. 12.3b.

The dissemination of ISESD and ESMD strong-motion databases was followed by important national and international strong-motion and seismic hazard projects in Europe and surrounding regions. Among these projects, the ITalian 
a

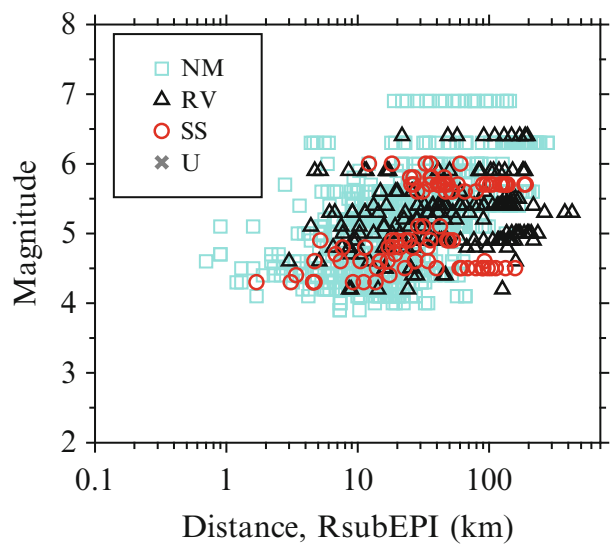

b



Fig. 12.4 Magnitude vs. distance scatters of (a) ITACA and (b) T-NSMP databases. The ITACA ${ }^{5}$ project compiled a total of 2,182 accelerograms from 1,004 events (Luzi et al. 2008) whereas T-NSMP studied 4,607 strong-motion records from 2,996 earthquakes recorded at 209 stations (Akkar et al. 2010). The symbols on the scatter plots show the distribution of fault mechanism in each database (Refer to the caption of Fig. 12.3 for abbreviations in the legends)

ACcelerometric Archive ${ }^{5}$ project (ITACA; http://itaca.mi.ingv.it; Luzi et al. 2008), the Turkish National Strong-Motion Project (T-NSMP; http://kyh.deprem.gov.tr; Akkar et al. 2010) and the HEllenic Accelerogram Database Project (HEAD; http:// www.itsak.gr; Theodulidis et al. 2004) are national efforts to compile, process and archive local (national) accelerometric data using state-of-the-art techniques. Figures $12.4 \mathrm{a}, \mathrm{b}$ show the magnitude vs. distance scatters of ITACA ${ }^{5}$ and T-NSMP databases as of the day they are released. These national projects improved the site characterization of strong-motion stations either by reassessing the existing shearwave velocity profiles and soil column lithology information or by utilizing invasive or noninvasive site exploration techniques to compute the unknown $\mathrm{V}_{\mathrm{S} 30}$ and other relevant site parameters (e.g., see Sandıkkaya et al. 2010 for site characterization methods of Turkish accelerometric archive). They also uniformly processed the strong-motion records by implementing a reliable and consistent data processing scheme. None of these data processing algorithms implemented constant filter cut-off frequencies to remove the high-frequency and low-frequency noise from the raw accelerograms.

The NERIES (Network of Research Infrastructures for European Seismology; www.neries-eu.org) and SHARE (Seismic Hazard HARmonization in Europe; www.share.eu.org) projects that are funded by European Council also contributed significantly to the integral efforts for collecting and compiling accelerometric data

\footnotetext{
${ }^{5}$ The ITACA database referenced in this article is now called as "ITACA v1" as a newer version is recently released on the same web site. The new release covers Italian strong-motion records from 1972 to the end of 2013.
} 
a



b

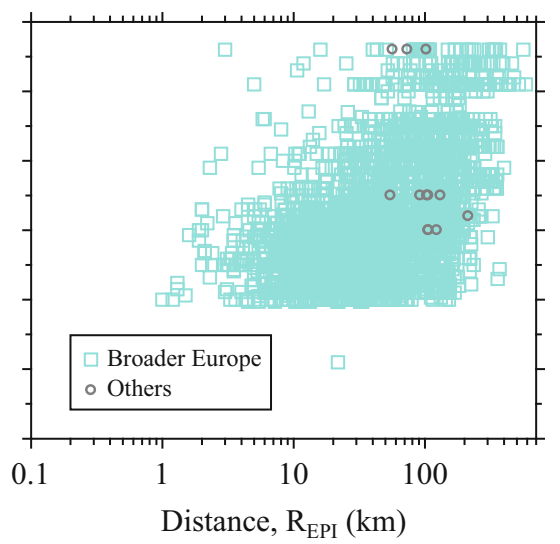

Fig. 12.5 Magnitude and distance distributions of (a) SHARE and (b) EMME strong-motion databases. The SHARE accelerograms from the broader Europe are shown in cyan to give a more clear view on the fraction of recordings from this region in the SHARE database. Same color codes are used in the EMME scatter plot to compare the strong-motion data distribution of broader Europe between these two databases

in the broader Europe. The NERIES project created a new infrastructure to collect, process and distribute near-real time accelerometric data from across Europe (www.seismicportal.eu). The SHARE project compiled a comprehensive strongmotion database (Yenier et al. 2010) by collecting worldwide shallow active crustal accelerometric data that includes recordings from ISESD, ESMD, ITACA and T-NSMP. The SHARE strong-motion database (13,500 records from 2,268 events recoded at 3,708 stations) was mainly used to test the candidate GMPEs for the seismic hazard calculations in SHARE project. The developers of SHARE database neither aimed for updating the metadata information nor developing a uniformly processed accelerometric data archive from the collected strong-motion recordings. The EMME (Earthquake Model of the Middle East Region; www.emme-gem.org) project that is funded by Global Earthquake Model (GEM) organization with objectives parallel to SHARE also established a strong-motion database for SACRs in the Middle East, Iran, Pakistan and Caucasus. The EMME strongmotion database that consists of 4,920 accelerograms from 1803 events is mainly used to identify the most proper GMPEs for hazard computations in the SACRs covered by the project. One of the major differences between the EMME and SHARE strong-motion databases is the uniform data processing implemented to the accelerograms in EMME. Besides, the earthquake and strong-motion station metadata information of the EMME database was reassessed systematically by the project partners (Akkar et al. 2014a). Figures 12.5a, b compare the magnitude and distance distributions of these two databases. Note that the magnitude and distance coverage of EMME strong-motion database is not as uniform as in the case of SHARE database. This is because the latter strong-motion inventory includes shallow 
active crustal earthquake accelerograms from the entire world. EMME strong-motion database is particularly rich in Iranian and Turkish recordings. When both databases are compared for accelerograms originating from the pan-European region, one may infer that EMME and SHARE databases can reveal significant amount of information about the characteristics of strong-motion data from this region.

The efforts put forward in the development of ISESD as well as other databases that are compiled from well-organized national and international projects had considerable impact on the improvement of accelerometric data quality in and around Europe. However, they suffer from certain drawbacks at different technical and operational levels. Although ISESD is an integrated database representing the strong-motion data archive of broader Europe, the poor strong-motion site characterization and the use of constant filter cut-offs in data processing are the major shortcomings of this database. The use of fixed filter cut-offs has been proven to be inappropriate as it may result in wrong representation of actual ground-motion frequency content of the recorded events (e.g., Akkar and Bommer 2006). The national strong-motion projects as well as EMME project took their precautions against such drawbacks but they implemented their own methodologies while assembling the databases. Thus, there is a lack of uniformity among these projects for metadata compilation and record processing for their integration under a single strong-motion database. The SHARE project did no attempt to homogenize the data processing of accelerograms. Improvements in earthquake and station metadata were also out of scope of SHARE. The recordings from the most recent pan-European earthquakes of engineering interest (e.g., 2009 L'Aquila Earthquake $\mathrm{M}_{\mathrm{w}}$ 6.3; 2011 Van Earthquake $\mathrm{M}_{\mathrm{w}}$ 7.1; 2011 Van-Edremit Earthquake $\mathrm{M}_{\mathrm{w}}$ 5.6; 2011 Kütahya-Simav Earthquake $M_{w}$ 5.9; 2010 Elazı $\breve{g}$-Kovancilar Earthquake $M_{w}$ 6.1) were either entirely or mostly discarded in the SHARE strong-motion database. The NERIES attempt was mostly limited to creating an infrastructure for integrated accelerometric data archive within from Europe. However, the proposed infrastructure focuses on the near-real time accelerograms that are hosted by NERIES portal (www.seismicportal.eu). These recordings are from the last decade with limited engineering significance (i.e. mostly small magnitude events). Moreover, the proposed data archiving and dissemination structure by NERIES is not entirely devised for the engineering needs of accelerometric data use.

Currently, the most up-to-date pan-European strong-motion database is RESORCE (Reference Database for Seismic Ground-Motion in Europe; resorceportal.eu) that is developed under the SIGMA (Seismic Ground Motion Assessment; projet-sigma.com) project. The primary motivation of RESORCE (Traversa et al. 2014) is to update and extend the ISESD accelerometric archive by using the information gathered from recently carried out strong-motion database projects as well as other relevant earthquake-specific studies in the literature. To this end, RESORCE made use of the already compiled metadata and waveform information from ITACA, T-NSMP, HEAD, SHARE, ISESD and ESMD. The information gathered from these databases were extended by considering the French (French Accelerometric Network; RAP; www-rap.obs.ujf-grenoble.fr) and Swiss (Swiss Seismological Service; SED; seismo.ethz.ch) accelerometric data that are from 
a

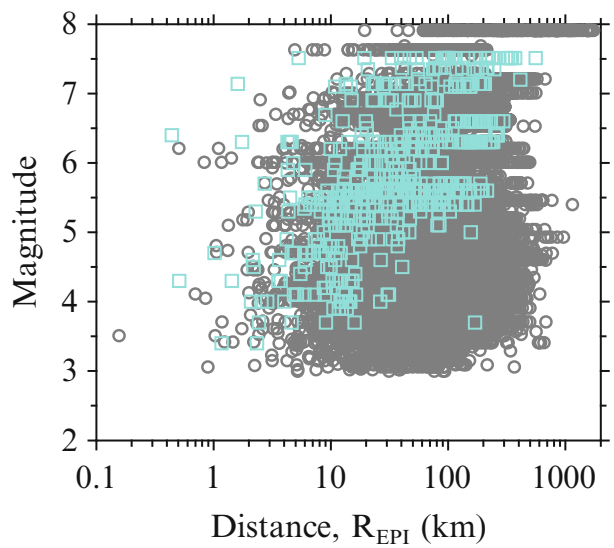

b

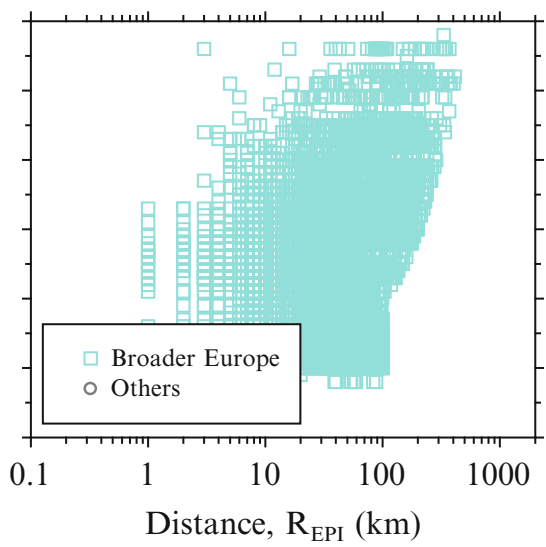

Fig. 12.6 Comparison of (a) NGA-West2 and (b) RESORCE strong-motion databases in terms of magnitude and distance distribution. The NGA-West 2 database contains 21,336 strong-motion recordings and only $2 \%$ of the data is from the pan-European region. The colored data given on the scatter plot of NGA-West2 show the pan-European accelerograms in this database

moderate-to-small magnitude events. The RESORCE developer team also did an extensive literature survey from peer-reviewed journals to improve the earthquake metadata information of earthquakes from the broader Europe. The uniform data processing of accelerograms following the discussions in Boore et al. (2012) as well as improved magnitude and source-to-site distance distributions constitute the other important achievements in RESORCE. The current data size of RESOCE is 5,882 accelerograms recorded from 1,814 events. The number of strong-motion stations included in RESORCE is 1,540. The magnitude and distance range covered by RESORCE is $2.8 \leq \mathrm{M}_{\mathrm{w}} \leq 7.8$ and $\mathrm{R}_{\mathrm{JB}} \leq 370 \mathrm{~km}$. The strategy followed in the compilation of RESORCE as well as its main features are given in Akkar et al. (2014d) and Sandikkaya and Akkar (2013). Figure 12.6 compares the magnitude vs. distance distribution of RESORCE and NGA-West2 database (Ancheta et al. 2014) that is used in the development of NGA-West2 GMPEs. The NGA-West 2 database covers a small fraction of accelerograms from the broader European region. Thus, the information provided in RESORCE, when used systematically with NGA-West2 database, can be a good basis to understand the significance of regional differences in shallow active crustal earthquakes between Europe and the other parts of the world. Table 12.1 compares the essential features of major strong-motion databases compiled from the recordings of broader Europe. The information presented in Table 12.1 once again confirms that RESORCE contains the most up-to-date data for the broader European region. The main sources of accelerograms are Turkey, Italy and Greece. Yet to be considered in RESORCE, for example, is to extend it by including the strong-motion data of other seismic prone countries in the region (e.g., Iran). To this end, EMME strong-motion database can be a good source but, as indicated previously, differences in database 





compilation between RESORCE and EMME would create difficulties while integrating these strong-motion archives.

The NERA (Network for European Research Infrastructures for Earthquake Risk Assessment and Mitigation; www.nera-eu.org) project builds a general framework on top of the above summarized efforts by proposing an integral infrastructure for a single, high-quality accelerometric database. The proposed system opts for the adoption of common data and metadata dissemination strategies and standards by forming a well-organized consortium among accelerometric data providers in and around Europe. The efforts to form this consortium have already started under Orfeus (Observatories and Research Facilities for European Seismology; www. orfeus-eu.org) with the contributions of NERA. The consortium will consist of the representatives of accelerometric data networks in the broader Europe for an integrated, sustainable and dynamically growing pan-European strong-motion database. In fact, the prototype of such accelerometric database has already been developed in NERA that is called as Engineering Strong Motion database (ESM_db). If the strong-motion consortium under Orfeus can be firmly established and if this consortium can maintain the so-called ESM_db with high standards, the pan-European endeavor to establish a long-term and reliable accelerometric data archive will make its most future promising progress for the last 40 years. The activities of NERA on accelerometric data networks as well as integrated pan-European accelerometric database are summarized in Akkar et al. (2014e).

\subsection{Ground-Motion Prediction Equations (GMPES) in the Broader European Region}

Bommer et al. (2010) and Akkar et al. (2014c) give a detailed review on some of the selected pan-European (global) GMPEs. This paper not only focuses on the evolution of global GMPEs in Europe and surroundings but also discusses the progress in the local European GMPEs by presenting overall statistics on some of the key aspects in these predictive models. We also make comparisons among the local and global GMPEs in Europe and extend these comparisons to NGA-West1 and NGA-West2 GMPEs to emphasize the differences (or similarities) between these ground-motion models. The statistics in this paper are primarily compiled from Douglas (2011). We used the statistics of other reports and papers for GMPEs that are published after Douglas (2011).

Figure 12.7 gives the number of GMPEs developed in the broader Europe as a function of time. The trends given for every decade depict that the number of GMPEs increases significantly after 1990 when strong-motion database compilation and dissemination is accelerated in Europe. (See discussions in the previous section). After 2000, the modelers started to develop GMPEs on elastic spectral ordinates rather than deriving equations only for PGA. This observation may suggest the increased significance of spectral ordinates in engineering design in 
Fig. 12.7 Number of GMPEs developed in the broader Europe between 1970 and present. The black vertical bars show the number of GMPEs estimating PGA only. The gray vertical bars display GMPEs estimating pseudoacceleration spectral ordinates (PSA) and PGA

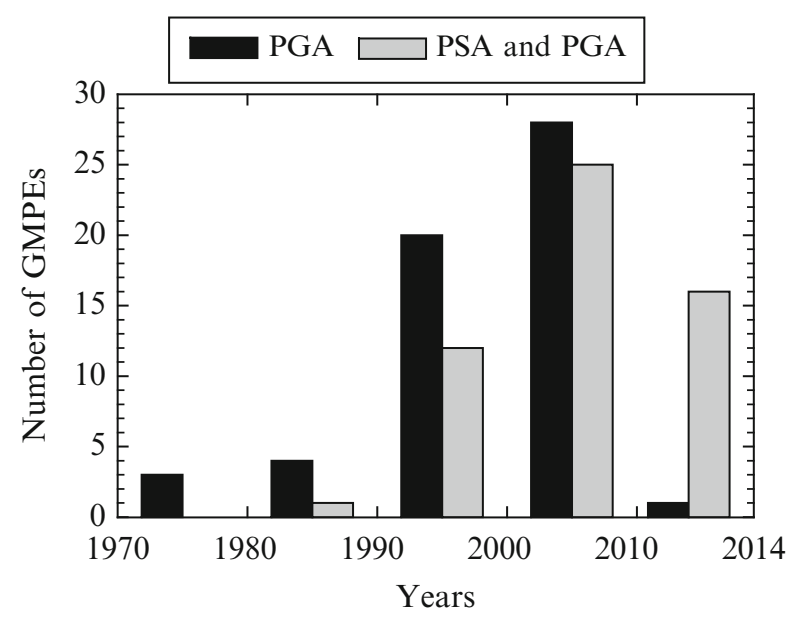

Fig. 12.8 Number of regression coefficients in GMPEs developed in the broader Europe between 1970 and present



Europe after 2000. It may also indicate the improvements in strong-motion databases after mid 90s because computation of spectral ordinates requires implementation of strong-motion data processing on the raw accelerometric data.

Figure 12.8 presents the modeling complexity of GMPEs in the broader Europe. The histogram in this figure shows the change in the number of regression coefficients as a function of time. The majority of functional forms $(\sim 80 \%)$ in Europe are relatively simple; consisting of regression coefficients up to $4\left(n_{r} \leq 4\right)$ or between 5 and $6\left(4<\mathrm{n}_{\mathrm{r}} \leq 6\right)$. GMPEs from the first group $\left(\mathrm{n}_{\mathrm{r}} \leq 4\right)$ are mainly developed before 2000 but their number is still significant in the decade following 2000. The second group GMPEs (i.e., $4<\mathrm{n}_{\mathrm{r}} \leq 6$ ) has become frequent after 90 s that coincides with the commencement of efforts for compiling higher quality databases in Europe. The functional forms with $4<\mathrm{n}_{\mathrm{r}} \leq 6$ generally account for the site effects on ground-motion estimates that constitute the major difference with respect to the GMPEs of $n_{r} \leq 4$. More complicated GMPEs (i.e., equations having $n_{r}>6$ ) became 

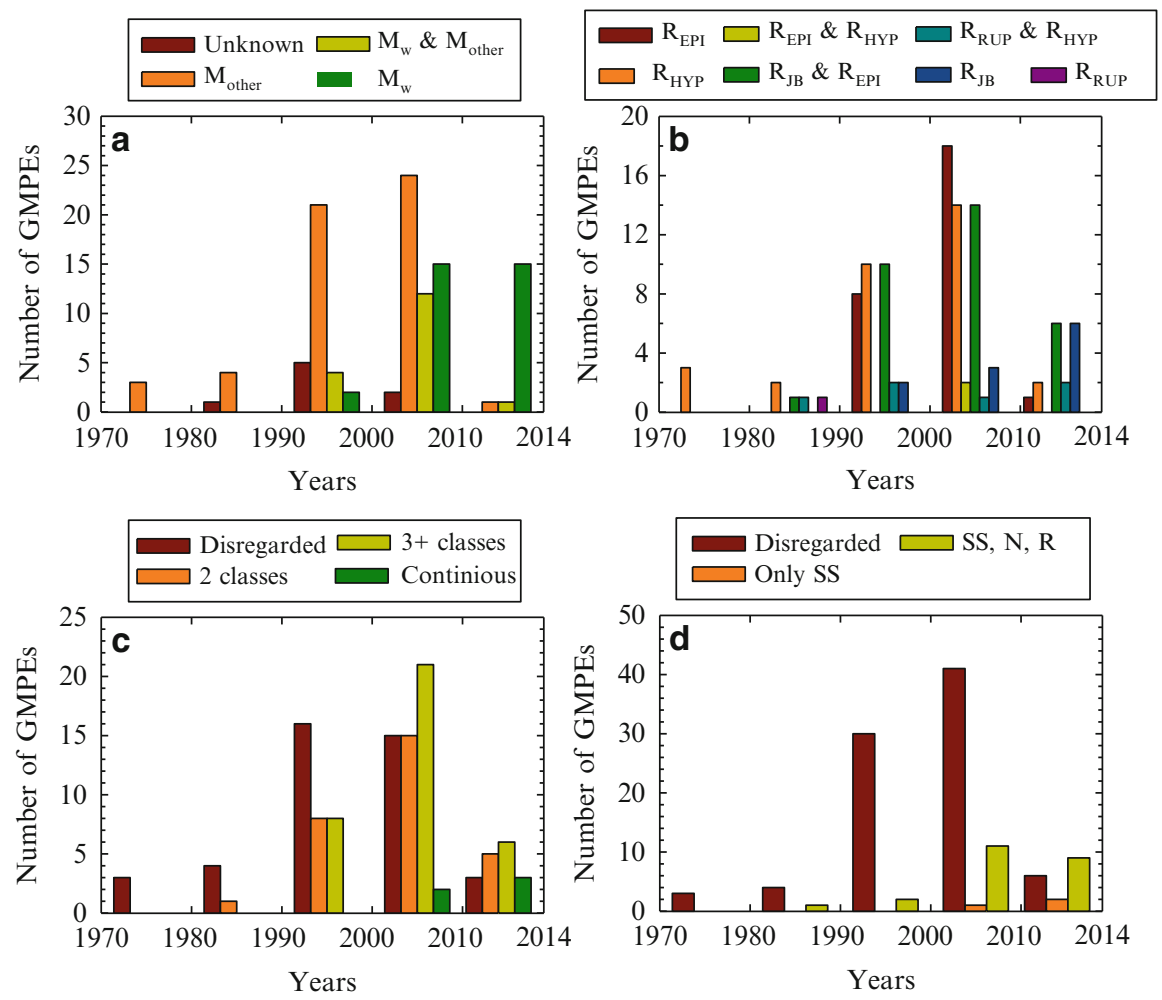

Fig. 12.9 Statistics on (a) preferred magnitude scaling, (b) preferred distance measure, (c) consideration of site conditions and (d) consideration of faulting type in GMPEs developed in the broader Europe. (Explanation of abbreviations in the legends: "Unknown" refers to GMPEs that do not indicate the type of magnitude in their functional forms, " $M_{w} \& M_{o t h e r}$ " indicates GMPEs combining moment magnitude and other magnitude scales in their functional forms, " $M_{\text {other }}$ " stands for GMPEs that use magnitude scales other than $M_{w}$ GMPEs that combine epicentral and hypocentral distances in their functional forms are abbreviated as " $R_{E P I} \& R_{H Y P}$." " $\mathrm{R}_{\mathrm{JB}} \& \mathrm{R}_{\mathrm{EPI}}$ " and " $\mathrm{R}_{\mathrm{RUP}} \& \mathrm{R}_{\mathrm{HYP}}$ " are used to indicate GMPEs using epicentral and Joyner-Boore distances and hypocentral and rupture distances, respectively. "Disregarded" stands for functional forms ignoring either site classification or style-of-faulting, "2 classes" and " $3+$ classes" indicate functional forms considering 2 and 3 or more site classes, respectively. "Only SS" describes GMPEs that treat strike-slip fault mechanism separately in their functional forms and "SS, N, R" is the abbreviation for functional forms that consider the effect of strike-slip, normal and reverse faults on ground-motions)

available after 2000 (more precisely in the last 10 years) because improvements in the database quality in and around Europe have come to a mature level following the dissemination of first pan-European strong-motion database CD-ROM by Ambraseys et al. (2004a). Currently, consideration of site effects and style-offaulting has almost become standard in the local and global European GMPEs.

Figure 12.9 shows another aspect of modeling complexity in the local and global European GMPEs by giving statistics on the specific features of estimator 
parameters. Figure 12.9a presents the time-dependent variation of preferred magnitude scaling in the functional forms. Figure $12.9 \mathrm{~b}$ displays a similar statistics on the preferred distance measures whereas Figs. 12.9c, d illustrate modeling of soil conditions and faulting type, respectively. The information given in these histograms complements the discussions on Fig. 12.8. The increased quality of strongmotion datasets leads to the utilization of more complicated estimator parameters for developing ground-motion models in the broader Europe. For example, the functional forms of GMPEs developed in the last 15 years generally use moment magnitude (Fig. 12.9a) and consider more rigorous schemes for site effects (Fig. 12.9c). In fact, some of the most recent local and global GMPEs in Europe describe the soil influence on ground motions by using continuous functions of $\mathrm{V}_{\mathrm{S} 30}$ (see Douglas et al. 2014). The use of point-source distance measures ${ }^{6}$ (i.e., epicentral distance, $R_{\text {epi }}$ and hypocentral distance, $R_{\text {hyp }}$ ) that are always appealing among the GMPE developers in Europe reduced after 90 s because strong-motion databases started to include extended-source distance measures (i.e., Joyner-Boore distance, $\mathrm{R}_{\mathrm{JB}}$ and rupture distance, $\mathrm{R}_{\text {rup }}$ ). To this end, GMPEs utilizing only extended-source distance metrics or those that combine extended- and point-source distance metrics have become more frequent in the last 15 years as displayed in Fig. 12.9b. Local and global European GMPEs that use hybrid distance measures (i.e., $\mathrm{R}_{\mathrm{RUP}} \& \mathrm{R}_{\mathrm{HYP}}$ or $\mathrm{R}_{\mathrm{JB}} \& \mathrm{R}_{\mathrm{EPI}}$ ) assume $\mathrm{R}_{\mathrm{RUP}} \approx \mathrm{R}_{\mathrm{HYP}}$ and $\mathrm{R}_{\mathrm{JB}} \approx \mathrm{R}_{\mathrm{EPI}}$ for small magnitude events (i.e., $\left.\mathrm{M}_{\mathrm{w}} \leq 5.5\right)$.

The discussions in the above paragraphs suggest that the efforts to improve strong-motion databases in the broader Europe result in enhanced local and global European GMPEs. Figure 12.10 shows the country-based distribution of predictive models for shallow active crustal earthquakes in the region of interest. Seismic prone countries that are active in database compilation are also active in developing GMPEs. As we have already emphasized, GMPEs developed from country-based (local) and global (multiple country) datasets are one of the topics of discussion among the seismological research community in Europe. The limitations in local strong-motion datasets due to uneven distribution of main estimator parameters as well as poor quality metadata and waveforms are the arguments augmenting the doubts about the reliability of GMPEs developed from such datasets. However, systematic attempts to improve the national strong-motion databases as well as international projects that make use of these well-studied national databases have brought another insight to such discussions. This point is demonstrated in Figs. 12.11 and 12.12. Figure 12.11 shows the median PGA estimates of local and pan-European GMPEs as a function of distance. The median PGA estimates are computed for a $90^{\circ}$ dipping strike-slip earthquake of $\mathrm{M}_{\mathrm{w}} 6$. The selected moment magnitude approximates the central magnitude value of the strong-motion

\footnotetext{
${ }^{6}$ The point-source distance measures do not consider the source geometry and approximates the ruptured fault segment as a point. The extended-source distance metrics account for the source geometry and can show the variation in ground-motion amplitudes more appropriately for large events at sites closer to the source.
} 


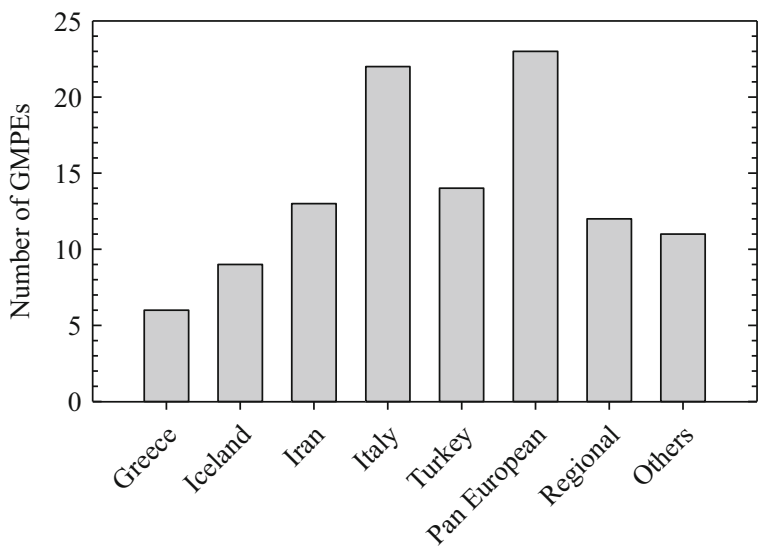

Fig. 12.10 Country-based distribution of GMPEs that are developed in the broader Europe. "Regional" GMPEs are developed from databases of specific regions in and around Europe (e.g., northern Italy, western Balkans, etc.). The label "Others" indicate GMPEs of European countries that are not listed on the horizontal axis of the figure (e.g., France, Switzerland, etc.). The "Pan European" class refers to global GMPEs developed for Europe and surroundings by using strong-motion recordings of multiple countries in and around Europe



Fig. 12.11 Median PGA trends of some selected Turkish, Italian and pan-European GMPEs for $\mathrm{M}_{\mathrm{w}} 6$ and for a generic rock site

databases used in the development of predictive models compared in these figures. The site considered for the fictitious earthquake scenario is assumed to be rock with $\mathrm{V}_{\mathrm{S} 30}=760 \mathrm{~m} / \mathrm{s}$. The hypocentral depth is taken as $9.7 \mathrm{~km}$. Note that we try to reduce the likely effects of epistemic uncertainty on the subject discussions by limiting the comparisons to median ground estimations and by using the central magnitude of the databases of compared GMPEs.

The local (country-based) GMPEs are selected from Turkey and Italy as they provide the largest amount of shallow active crustal earthquake recordings to pan-European databases. The ground-motion predictive models from Turkey are Akkar and Çağnan (2010) (AC10) and Kale et al. (2015) (KAAH15). These two recent GMPEs were developed from different versions of strong-motion datasets 

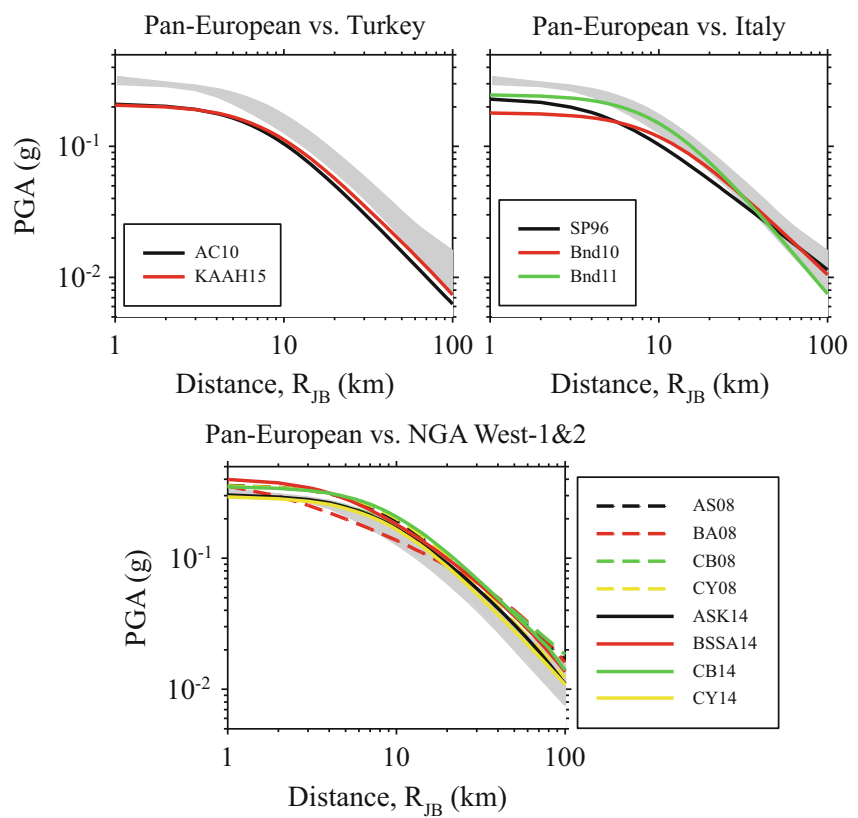

Fig. 12.12 Comparisons of Turkish, Italian as well as NGA-West1 and NGA-West2 GMPEs with pan-European predictive models for the earthquake scenario given in Fig. 12.11. The gray shaded areas indicate the lower and upper bound median PGA estimates of pan-European GMPEs

developed from the whole country. In a similar manner, Sabetta and Pugliese (1996) (SP96) and Bindi et al. (2010, 2011) (Bnd10, Bnd11) GMPEs are selected for Italy as their datasets represent the progressive improvements of strong-motion data quality in Italy for the last two decades. The pan-European GMPEs used in the comparative plots [Ambraseys et al. 1996 (Amb96); Ambraseys et al. 2005 (Amb05); Akkar and Bommer 2010 (AB10); Akkar et al. 2014c (ASB14) and Bindi et al. 2014 (Bnd14)] are among the best representatives of global European models at the time when they were developed. The horizontal component definition is geometric mean (GM) in the comparative plots. If any one of the above predictive models is originally developed for a different horizontal component definition, we used the Beyer and Bommer (2006) empirical relationships for its modification for GM. We also used the geometry of fictitious fault to utilize each GMPE with its original distance metric. However, we preferred using Joyner-Boore distance $\left(\mathrm{R}_{\mathrm{JB}}\right)$ in the plots because the distance measure of most of the selected GMPEs for comparison is $\mathrm{R}_{\mathrm{JB}}$.

The median PGA curves in Fig. 12.11 depict that the Turkish GMPEs follow each other closely for $M_{w} 6$. We observe the similar behaviors within the Italian and pan-European GMPEs. The distance-dependent PGA amplitude estimations of these groups show discrepancies with respect to each other. These observations can indicate the existence of regional differences that is verified by another set of comparisons in Fig. 12.12. 
The upper row panels in Fig. 12.12 compare the median PGA estimates from Turkish (left panel) and Italian (right panel) GMPEs with the upper and lower bound median PGA estimates of pan-European GMPEs (represented as the gray shaded area in the panels). Note that the earthquake scenario and the predictive models in Fig. 12.12 are the same ones used in Fig. 12.11. The upper and lower bound median PGA estimates of pan-European GMPEs are compared with those predicted from the NGA-West1 and NGA-West2 GMPEs in the bottom panel of Fig. 12.12. The NGA-West1 GMPEs used in the comparative plots are Abrahamson and Silva (2008) (AS08), Boore and Atkinson (2008) (BA08), Campbell and Bozorgnia (2008) (CB08) and Chiou and Youngs (2008) (CY08). Abrahamson et al. (2014) (ASK14), Boore et al. (2014) (BSSA14), Campbell and Bozorgnia (2014) (CB14) and Chiou and Youngs (2014) (CY14) are the NGA-West2 GMPEs (successors of NGA-West1). The comparisons point differences in the median PGA estimates between the local vs. global European GMPEs. The PGA estimates of global European GMPEs also differ with respect to NGA-West1 and NGA-West2 GMPEs. The level of differences varies as a function of distance. The differences between the local and global GMPE estimates can be interpreted as the significance of regional effects that should be accounted for while developing consistent predictive models in the broader Europe. The discrepancy between the global NGA and pan-European GMPEs advocate the implementation of a similar strategy while estimating the ground-motion amplitudes in the SACRs of broader Europe and the other parts the world. We note that the remarks highlighted from these comparisons should be augmented by further statistical tests to reach more conclusive results about the regional differences in different scales.

\subsection{Implications of Using Local and Global GMPES from Broader Europe in Seismic Hazard}

The discussions in the previous section that show the differences between recent local and global GMPEs are deliberately based on a single earthquake scenario $\left(\mathrm{M}_{\mathrm{w}}\right.$ 6; central magnitude) and for median PGA. The selected earthquake scenario and comparisons on median ground-motion estimates would be a first-order approximation to give a clear idea on the level of discrepancies between the considered local and global GMPEs. However, they will fail to give an overall picture to understand how these differences would map onto probabilistic seismic hazard assessment (PSHA). Thus, using the same local and global European GMPEs of the previous case study we present the PSHA results of two specific locations featuring different seismic patterns. We note that running PSHA would show the influence of GMPE sigma and magnitude interval on the estimated ground motions for a given exceedance probability. Moreover, as the local and global European GMPEs discussed in the previous section are frequently used in Europe, the presented PSHA results would be the realistic indicators of how and when the 


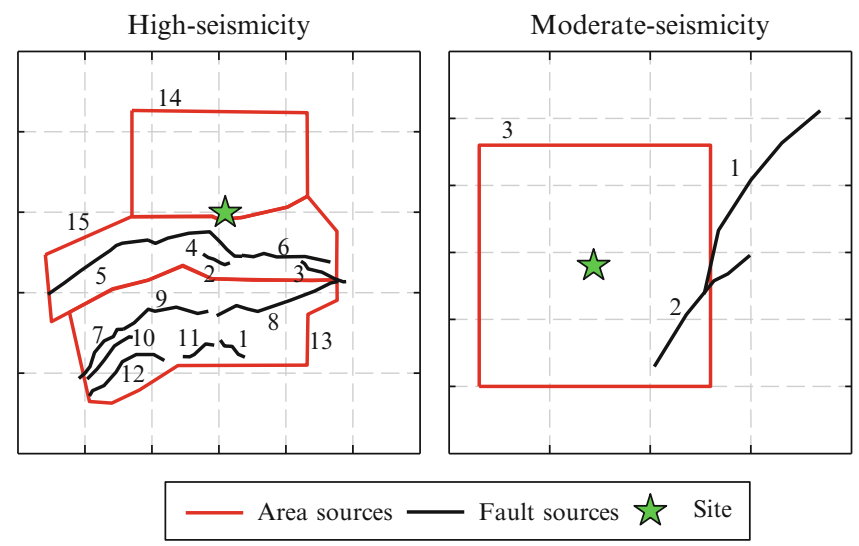

Fig. 12.13 High-seismicity (left panel) and moderate-seismicity (right panel) sites and corresponding seismic source layouts used in the PSHA case studies

local and pan-European GMPEs would differ from each other as a function of annual exceedance rate and for varying levels of seismicity. We also include the PSHA results of NGA-West2 GMPEs into the comparisons to augment the discussions for the ground-motion estimates between global European and non-European GMPEs. In essence, these case studies will convey a more complete but at the same time more complicated picture about the effects of using local and global European GMPEs on seismic hazard assessment in the broader Europe.

Our PSHA case studies not only focus on PGA but also consider pseudo elastic spectral accelerations (PSA) at $\mathrm{T}=0.2 \mathrm{~s}, \mathrm{~T}=1.0 \mathrm{~s}$ and $\mathrm{T}=2.0 \mathrm{~s}$ for a broader view about the topic of discussion. PGA is currently the anchor spectral ordinate to describe design ground-motion demand in Eurocode 8 (CEN 2004) whereas the US codes (e.g., ASCE 2010) use spectral accelerations at $\mathrm{T}=0.2 \mathrm{~s}$ and $\mathrm{T}=1.0 \mathrm{~s}$ for design spectrum. PSA at $\mathrm{T}=2.0 \mathrm{~s}$ would show the estimated seismic hazard trends for local and global European GMPEs towards long-period spectral ordinates. Figure 12.13 shows the layouts of two locations used in the PSHA case studies. The location on the left panel is in the vicinity of active faults with significant seismicity. The seismic source pattern is complicated. The activity of seismic sources on the right panel is moderate and the configuration of seismic sources is simpler.

We call these sites (regions) as high seismicity (left panel) and moderate seismicity (right panel). Table 12.2 lists the seismic source parameters and their corresponding values used in PSHA modeling. The seismic source characterization is compiled from different studies in the literature for the locations of interest and they are within the acceptable ranges to reflect the target seismicity level for each study region. Figure 12.14 displays the comparisons of moderate-seismicity hazard curves between Turkish vs. pan-European GMPEs (Fig. 12.14a) and Turkish vs. NGA-West2 GMPEs (Fig. 12.14b). Figure 12.15 displays the same comparisons for the high-seismicity region. The gray shaded areas in these figures display the upper 
Table 12.2 Seismic source parameters used in the PSHA modeling of high-seismicity and moderate-seismicity sites

\begin{tabular}{|c|c|c|c|c|c|c|c|}
\hline & $\begin{array}{l}\text { Source } \\
\text { ID }\end{array}$ & $\begin{array}{l}\text { Type }{ }^{\mathrm{a}} \text { - dip } \\
\text { angle }\end{array}$ & $\mathrm{B}$ & $\begin{array}{l}\dot{S} \text { (month/ } \\
\text { year) }\end{array}$ & $v_{M \min }{ }^{\mathrm{b}}$ & $M_{\text {min }}$ & $M_{\max }$ \\
\hline \multirow{3}{*}{$\begin{array}{l}\text { Moderate } \\
\text { Seismicity }\end{array}$} & 1 & Strike slip- $90^{\circ}$ & 0. & 2.0 & - & 6.2 & 6.8 \\
\hline & 2 & Strike slip- $90^{\circ}$ & 0. & 6.0 & - & 7.0 & 7.5 \\
\hline & 3 & $\begin{array}{l}\text { Area (strike } \\
\text { slip) }\end{array}$ & 2.28 & - & 1.52 & 4.0 & 5.9 \\
\hline \multirow[t]{15}{*}{ High seismicity } & 1 & Strike slip- $90^{\circ}$ & 0. & 3.0 & - & 6.5 & 7.0 \\
\hline & 2 & Normal- $60^{\circ}$ & 0. & 18.5 & - & 6.5 & 7.0 \\
\hline & 3 & Strike slip- $90^{\circ}$ & 0. & 24.0 & - & 6.5 & 7.2 \\
\hline & 4 & Strike slip- $90^{\circ}$ & 0. & 24.0 & - & 6.5 & 7.5 \\
\hline & 5 & Strike slip- $90^{\circ}$ & 0. & 24.0 & - & 6.5 & 7.5 \\
\hline & 6 & Strike slip- $90^{\circ}$ & 0. & 24.0 & - & 6.5 & 7.5 \\
\hline & 7 & Strike slip- $90^{\circ}$ & 0. & 3.0 & - & 6.5 & 7.2 \\
\hline & 8 & Strike slip- $90^{\circ}$ & 0. & 6.0 & - & 6.5 & 7.5 \\
\hline & 9 & Strike slip- $90^{\circ}$ & 0. & 4.5 & - & 6.5 & 7.5 \\
\hline & 10 & Strike slip- $90^{\circ}$ & 0. & 3.0 & - & 6.5 & 7.5 \\
\hline & 11 & Strike slip- $90^{\circ}$ & 0. & 3.0 & - & 6.5 & 7.0 \\
\hline & 12 & Strike slip- $90^{\circ}$ & 0. & 3.0 & - & 6.5 & 7.2 \\
\hline & 13 & $\begin{array}{l}\text { Area (strike } \\
\text { slip) }\end{array}$ & 2.03 & - & 2.08 & 4.0 & 6.4 \\
\hline & 14 & $\begin{array}{l}\text { Area (strike } \\
\text { slip) }\end{array}$ & 1.44 & - & 0.243 & 4.0 & 6.4 \\
\hline & 15 & $\begin{array}{l}\text { Area (strike } \\
\text { slip) }\end{array}$ & 1.86 & - & 2.34 & 4.0 & 6.4 \\
\hline
\end{tabular}

${ }^{a}$ Annual slip rate

${ }^{\mathrm{b}}$ Minimum activity

and lower limits of hazard curves computed from the selected Turkish GMPEs (AC10 and KAAH15). The comparative plots for moderate seismicity (Fig. 12.14) depict that both pan-European and NGA-West2 GMPEs tend to give larger values for very short and short periods (i.e., PGA and PSA at $\mathrm{T}=0.2 \mathrm{~s}$ ) with respect to Turkish GMPEs. The NGA-West2 GMPEs estimate lesser ground motions towards longer periods whereas the pan-European models yield similar spectral accelerations as of Turkish GMPEs at longer periods (i.e., $\mathrm{T}=1.0 \mathrm{~s}$ and $\mathrm{T}=2.0 \mathrm{~s}$ ). The pan-European GMPEs yield larger spectral values when compared to Turkish GMPEs for the high-seismicity site (Fig. 12.15) for the spectral ordinates considered in the comparisons. The hazard trends between the Turkish and NGA-West2 GMPEs in the high-seismicity region show similarities with those of Fig. 12.14b (i.e., moderate-seismicity case). However, the hazard estimates of these two sets of predictive models (i.e., NGA-West2 and Turkish GMPEs) are closer to each other for the high-seismicity case. The discrepancy between the Turkish and global GMPEs (both European and non-European) increases with decreasing annual exceedance rates in most cases. 
a

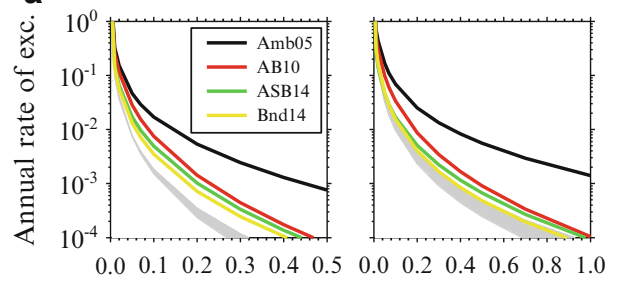

PGA (g)

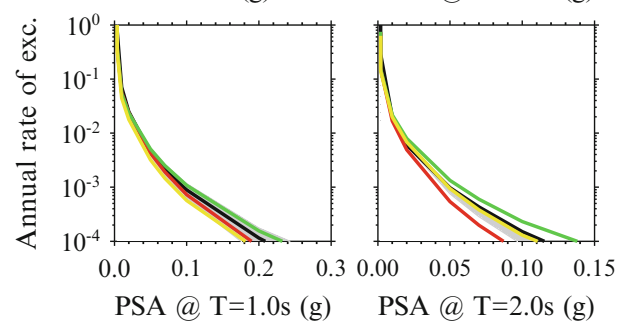

b

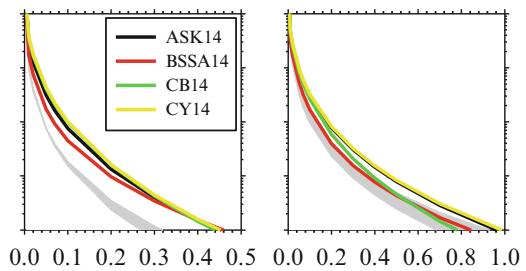

PGA (g)

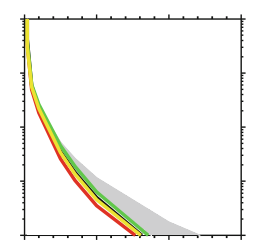

PSA@ $\mathrm{T}=0.2 \mathrm{~s}(\mathrm{~g})$



Fig. 12.14 Comparisons of hazard curves for PGA, PSA at $T=0.2 \mathrm{~s}, \mathrm{~T}=1.0 \mathrm{~s}$ and $\mathrm{T}=2.0 \mathrm{~s}$ between (a) Turkish vs. pan-European GMPEs and (b) Turkish vs. NGA-West2 GMPEs for the chosen moderate-seismicity region
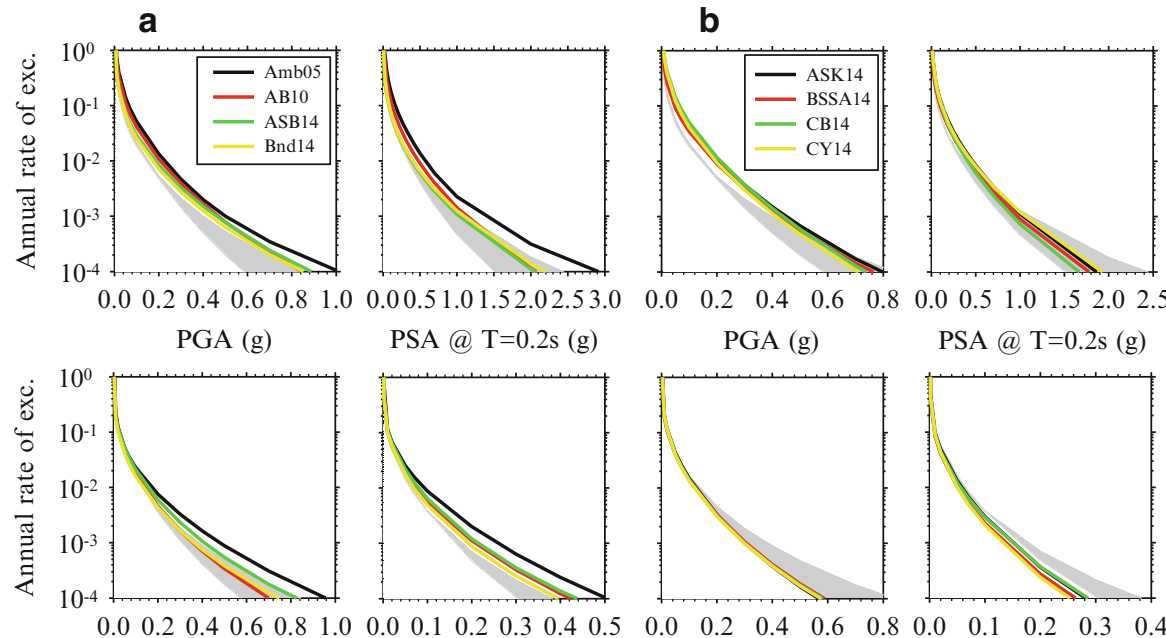

PSA@ T=0.2s (g)

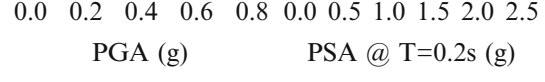

PSA @ T=1.0s (g) PSA @ T=2.0s (g)
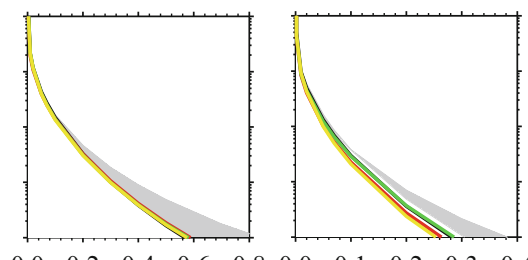

$\begin{array}{llllllllll}0.0 & 0.2 & 0.4 & 0.6 & 0.8 & 0.0 & 0.1 & 0.2 & 0.3 & 0.4\end{array}$ PSA @ T=1.0s (g) PSA @ T=2.0s (g)

Fig. 12.15 Comparisons of hazard curves for PGA, PSA at $\mathrm{T}=0.2 \mathrm{~s}, \mathrm{~T}=1.0 \mathrm{~s}$ and $\mathrm{T}=2.0 \mathrm{~s}$ between (a) Turkish vs. pan-European GMPEs and (b) Turkish vs. NGA-West2 GMPEs for the chosen high-seismicity region 




Fig. 12.16 Same as Fig. 12.14 but the comparisons are between (a) Italian vs. pan-European GMPEs and (b) Italian vs. NGA-West2 GMPEs for moderate seismicity
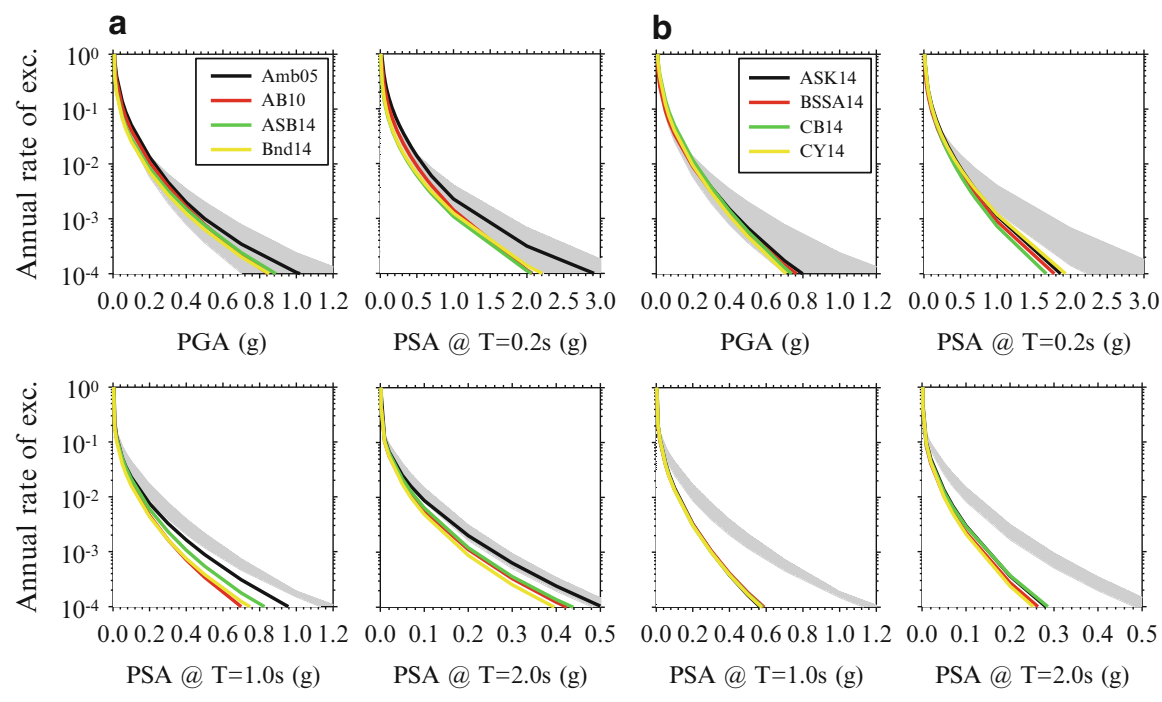

Fig. 12.17 Same as Fig. 12.15 but the comparisons are between (a) Italian vs. pan-European GMPEs and (b) Italian vs. NGA-West2 GMPEs for high-seismicity case

Figures 12.16 and 12.17 make similar comparisons as of Figs. 12.14 and 12.15, respectively, for Italian vs. pan-European and Italian vs. NGA-West2 groundmotion equations. Bnd10 and Bnd11 models are used as the Italian GMPEs because they are developed from the last generation Italian ground-motion datasets. The 
a
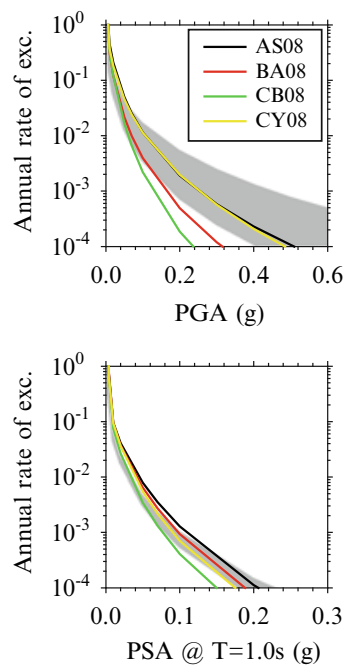

b
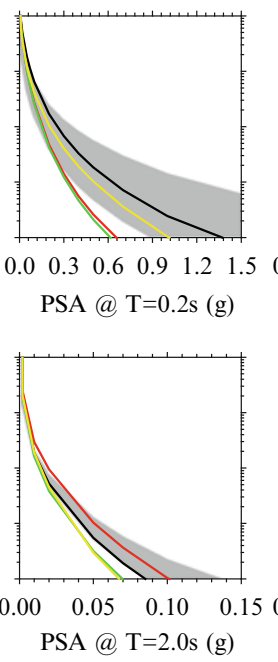
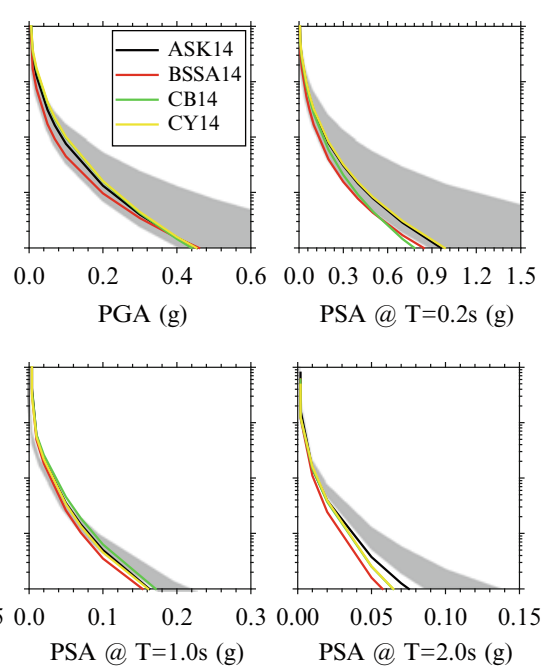

Fig. 12.18 Same as Figs. 12.14 and 12.16 but comparisons are between (a) NGA-West 1 vs. pan-European GMPEs and (b) NGA-West2 vs. pan-European GMPEs for moderate-seismicity region

comparisons in Figs. 12.16a, b suggest that the global (i.e., pan-European and NGA-West2 models) and Italian GMPEs yield similar spectral accelerations for PGA and PSA at $T=0.2 \mathrm{~s}$. The only exception to this observation is the Amb05 pan-European model that yields significantly different acceleration values with respect to the rest of the GMPEs. ${ }^{7}$ (in fact, Amb05 depicts a significant difference with respect to Turkish GMPEs for short and very-short spectral ordinates as shown in Fig. 12.14). The pan-European and NGA-West2 GMPEs tend to estimate smaller with respect to Italian GMPEs towards longer period spectral acceleration values (i.e., $\mathrm{T}=1.0 \mathrm{~s}$ and $\mathrm{T}=2.0 \mathrm{~s}$ ). The level of underestimation is more significant in NGA-West2 GMPEs. We note that the trends summarized in Fig. 12.16 are fairly valid for Fig. 12.17 as well. In both cases (i.e., moderate- and high-seismicity locations), the decrease in annual exceedance rates triggers larger long-period PSA differences between the Italian and global GMPEs.

The last comparative plots in this section show the differences between the hazard estimates of pan-European, NGA-West1 and NGA-West2 GMPEs. The format and order of the comparative plots follow the previous figures. Figure 12.18 compares the NGA-West1 (Fig. 12.18a) and NGA-West2 (Fig. 12.18b) GMPEs with the pan-European GMPEs for moderate-seismicity case. Figure 12.19 does the same comparison for high seismicity. The shaded areas in these plots represent the

\footnotetext{
${ }^{7}$ The magnitude-dependent standard deviation of Amb05 attains very large values at small magnitudes that govern the moderate-seismicity case. Although we did not explore the computed hazard results in great detail, we believe that the large sigma of Amb05 at small magnitudes is the major reason behind the inflated short and very-short period PSA by this GMPE.
} 
a
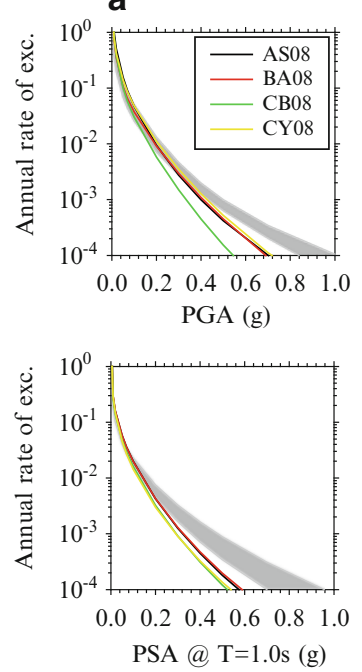



0.00 .51 .01 .52 .02 .53 .0 PSA @ T=0.2s (g)

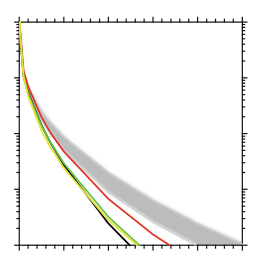



b
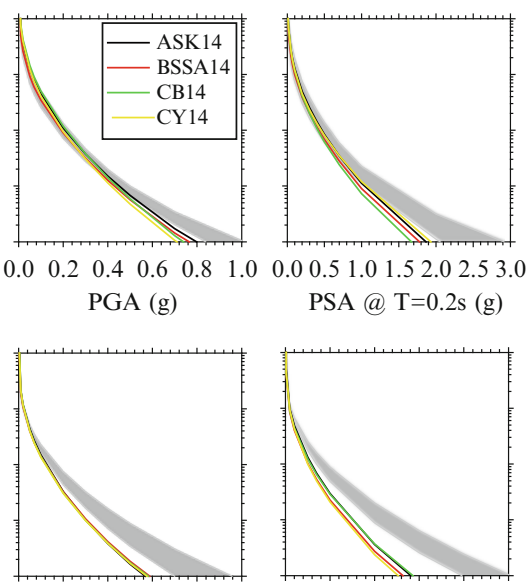

PSA @ T=1.0s (g)

\section{PSA @ T=2.0s (g)}

Fig. 12.19 Same as Figs. 12.15 and 12.17 but comparisons are between (a) NGA-West1 vs. pan-European GMPEs and (b) NGA-West2 vs. pan-European GMPEs for high-seismicity region

upper and lower limits of hazard curves computed from the pan-European GMPEs. The comparisons in these figures indicate that NGA models tend to yield smaller spectral accelerations with respect to pan-European GMPEs. The small accelerations are generally more pronounced for NGA-West2 GMPEs. The discrepancy between the European and non-European global GMPEs increases with decreasing annual exceedance rates. This observation is more notable towards longer period spectral accelerations. The underestimations between these two groups of predictive models are also more definite in the high-seismicity case (Fig. 12.19).

The overall discussions in this section indicate that there are differences between the hazard estimates of local and global GMPEs developed from the ground-motion sets of broader Europe. The discrepancies depend on the level of seismicity, annual exceedance rate and spectral period. They are generally significant with decreasing annual exceedance rates (i.e., less frequent but at the same time more critical earthquakes). Note that the local and global GMPEs employed in these case studies are recent and they are developed from reliable local and global databases of Europe. To this end, the highlighted observations from these case studies may partially point the consequential effect of regional differences on seismic hazard. 


\subsection{Conclusions}

The metadata information as well as waveform quality of local and global databases compiled in the broader Europe have shown considerable improvements during the last 15 years due to the grants raised by national and international research programs. This progress has reflected on to the quality and quantity of local and global European GMPEs that are developed in the same period. Our basic analyses indicate that there are differences in the ground-motion estimates of these local and global European GMPEs although their databases are now much more reliable with respect to past. Our comparisons also suggest the existence of similar differences between non-European (NGA) and European global GMPEs. Some part of the observed discrepancies between these ground-motion models can be the attributes of regional differences. Thus, the seismic hazard expert should be aware of such differences among the local and global GMPEs while considering a proper set of GMPEs for the region (site) of interest. Identification of proper GMPEs partly relies on assembling test-bed databases from the strong-motion recordings of the region of interest. Because these specific databases are used for evaluating the candidate GMPEs to establish the most suitable GMPE set for hazard assessment. Such a comprehensive and specific data collection can be done from reliable pan-European strong-motion data archives. Currently, there are ongoing serious efforts among the European research community to establish a good infrastructure for a long-term and integrated accelerometric data archive within the broader Europe. This endeavor is evolving under Orfeus in a systematic manner. The success of this attempt will also lead to the development of more refined GMPEs for the broader Europe for a more proper consideration of regional effects. Such predictive models would certainly increase the accuracy of seismic hazard assessment in Europe and surroundings.

Open Access This chapter is distributed under the terms of the Creative Commons Attribution Noncommercial License, which permits any noncommercial use, distribution, and reproduction in any medium, provided the original author(s) and source are credited.

\section{References}

Abrahamson N, Silva W (2008) Summary of the Abrahamson \& Silva NGA ground-motion relations. Earthq Spectra 24(1):67-97

Abrahamson N, Silva W, Kamai R (2014) Summary of the ASK14 ground-motion relation for active crustal regions. Earthq Spectra 30(3):1025-1055

Akkar S, Bommer JJ (2006) Influence of long-period filter cut-off on elastic spectral displacements. Earthq Eng Struct Dyn 35:1145-1165

Akkar S, Bommer JJ (2007) Empirical prediction equations for peak ground velocity derived from strong-motion records from Europe and the Middle East. Bull Seismol Soc Am 97(2):511-530 
Akkar S, Bommer JJ (2010) Empirical equations for the prediction of PGA, PGV and spectral accelerations in Europe, the Mediterranean region and the Middle East. Seismol Res Lett 81(2):195-206

Akkar S, Çağnan Z (2010) A local ground-motion predictive model for Turkey and its comparison with other regional and global ground-motion models. Bull Seismol Soc Am 100 (6):2978-2995

Akkar S, Çağnan Z, Yenier E, Erdogan Ö, Sandikkaya MA, Gülkan P (2010) The recently compiled Turkish strong-motion database: preliminary investigation for seismological parameters. J Seismol 14:457-479

Akkar S, Kale Ö, Ansari A, Durgaryan R, Askan Gündoğan A, Hamzehloo H, Harmandar E, Tsereteli N, Waseem M, Yazjeen T, Y1lmaz MT (2014a) EMME strong-motion database serving for predictive model selection to EMME ground-motion logic-tree applications. Second European conference on earthquake engineering and seismology, İstanbul, Abstract no. 3220

Akkar S, Sandikkaya MA, Аy BÖ (2014b) Compatible ground-motion prediction equations for damping scaling factors and vertical-to-horizontal spectral amplitude ratios for the broader Europe region. Bull Earthq Eng 12(1):517-547

Akkar S, Sandikkaya MA, Bommer JJ (2014c) Empirical ground-motion models for point- and extended-source crustal earthquake scenarios in Europe and the Middle East. Bull Earthq Eng 12(1):359-387

Akkar S, Sandikkaya MA, Şenyurt M, Azari Sisi A, Ay BÖ, Traversa P, Douglas J, Cotton F, Luzi L, Hernandez B, Godey S (2014d) Reference database for seismic ground-motion in Europe (RESORCE). Bull Earthq Eng 12:311-339

Akkar S, Bossu R, Cauzzi C, Clinton J, D'amico M, Van Eck T, Frobert L, Godey S, Gueguen P, Kästli P, Luzi L, Pacor F, Pequegnat C, Puglia R, Russo E, Sleeman R (2014e) Network of European research infrastructures for earthquake risk assessment and mitigation (NERA) networking accelerometric networks and Sm Data Users (NA3). Second European conference on earthquake engineering and seismology, İstanbul

Ambraseys NN (1975) Trends in engineering seismology in Europe. In: Proceedings of fifth European conference on earthquake engineering, vol 3. pp 39-52, September 22-25, İstanbul, Turkey

Ambraseys NN (1990) Uniform magnitude re-evaluation of European earthquake associated with strong-motion records. Earthq Eng Struct Dynam 19:1-20

Ambraseys NN, Bommer JJ (1990) Uniform magnitude re-evaluation for the strong-motion database of Europe and adjacent regions. Eur Earthq Eng 4:3-16

Ambraseys NN, Bommer JJ (1991) Database of European strong-motion records. Eur Earthq Eng 5:18-37

Ambraseys NN, Douglas J, Sigbjörnsson R, Berge-Thierry C, Suhadolc P, Costa G, Smit PM (2004a) Dissemination of European strong-motion data, vol 2. In: Proceedings of the 13th world conference on earthquake engineering, Vancouver, British Columbia

Ambraseys NN, Smit P, Douglas J, Margaris B, Sigbjörnsson R, Olafsson S, Suhadolc P, Costa G (2004b) Internet site for European strong-motion data. Boll Geofis Teor Appl 45:113-129

Ambraseys NN, Douglas J, Sarma SK, Smit PM (2005) Equations for the estimation of strong ground motions from shallow crustal earthquakes using data from Europe and the Middle East: horizontal peak ground acceleration and spectral acceleration. Bull Earthq Eng 3(1):1-53

Ambraseys NN, Simpson KA, Bommer JJ (1996) Prediction of horizontal response spectra in Europe. Earthq Eng Struct Dynam 25(4):371-400

Ambraseys N, Smit P, Berardi R, Rinaldis D, Cotton F, Berge-Thierry C (2000) Dissemination of European strong-motion data, CD-ROM collection. European Commission, Directorate General XII, Science, Research and Development, Environment and Climate Programme, Bruxelles

ASCE (2010) Minimum design loads for buildings and other structures (7-10). American Society of Civil Engineers, ASCE/SEI7-10 
Ancheta TD, Robert BD, Stewart PS, Seyhan E, Silva WJ, Chiou BSJ, Wooddell KE, Graves RW, Kottke AR, Boore DM, Kishida T, Donahue JL (2014) NGA-West 2 database. Earthq Spectra 30(3):989-1005

Atkinson GM, Morrison M (2009) Observations on regional variability in ground-motion amplitudes for small-to-moderate earthquakes in North America. Bull Seismol Soc Am 99(4):2393-2409

Bindi D, Luzi L, Massa M, Pacor F (2010) Horizontal and vertical ground motion prediction equations derived from the Italian accelerometric archive (ITACA). Bull Earthq Eng 8:1209-1230

Bindi D, Massa M, Luzi L, Ameri G, Pacor F, Puglia R, Augliera P (2014) Pan-European groundmotion prediction equations for the average horizontal component of PGA, PGV, and 5\%-damped PSA at spectral periods up to $3.0 \mathrm{~s}$ using the RESORCE dataset. Bull Earthq Eng 12:391-430

Bindi D, Pacor F, Luzi L, Puglia R, Massa M, Ameri G, Paolucci R (2011) Ground motion prediction equations derived from the Italian strong motion database. Bull Earthq Eng 9:1899-1920

Beyer B, Bommer JJ (2006) Relationships between median values and between aleatory variabilities for different definitions of the horizontal component of motion. Bull Seismol Soc Am 96 (4A):1512-1522

Bommer JJ, Akkar S, Kale Ö (2011) A model for vertical-to-horizontal response spectral ratios for Europe and the Middle East. Bull Seismol Soc Am 101(4):1783-1806

Bommer JJ, Stafford PJ, Akkar S (2010) Current empirical ground-motion prediction equations for Europe and their application to Eurocode 8. Bull Earthq Eng 8:5-26

Boore DM, Atkinson G (2008) Ground-motion prediction equations for the average horizontal component of PGA, PGV, and 5\%-damped PSA at spectral periods between $0.01 \mathrm{~s}$ and 10.0 s. Earthq Spectra 24(1):99-138

Boore DM, Azari Sisi A, Akkar S (2012) Using pad-stripped acausally filtered strong-motion data. Bull Seismol Soc Am 102:751-760

Boore DM, Stewart JP, Seyhan E, Atkinson GM (2014) NGA-West 2 equations for predicting PGA, PGV, and 5\%-damped PSA for shallow crustal earthquakes. Earthq Spectra 30(3):10571085

Bozorgnia Y, Abrahamson NA, Al Atik L, Ancheta TD, Atkinson GM, Baker JW, Baltay A, Boore DM, Campbell KW, Chiou BSJ et al (2014) NGA-West2 Research Project. Earthq Spectra 30(3):973-987

Bragato PL, Slejko D (2005) Empirical ground-motion attenuation relations for the eastern Alps in the magnitude range 2.5-6.3. Bull Seismol Soc Am 95(1):252-276

Campbell KW, Bozorgnia Y (2008) NGA ground motion model for the geometric mean horizontal component of PGA, PGV, PGD and 5\% damped linear elastic response spectra for periods ranging from 0.01 to $10 \mathrm{~s}$. Earthq Spectra 24(1):139-171

Campbell KW, Bozorgnia Y (2014) NGA-West2 ground motion model for the average horizontal components of PGA, PGV, and 5\%-damped linear acceleration response spectra. Earthq Spectra. 30(3): 1087-1115

CEN (2004) Eurocode 8: design of structures for earthquake resistance—part 1: General rules, seismic actions, and rules for buildings, EN1998-1:2004. Comité Européen de Normalisation, Brussels

Chiou BS-J, Youngs RR (2008) An NGA model for the average horizontal component of peak ground motion and response spectra. Earthq Spectra 24(1):173-215

Chiou BS-J, Youngs RR (2014) Update of the Chiou and Youngs NGA model for the average horizontal component of peak ground motion and response spectra. Earthq Spectra

Chiou BS-J, Youngs RR, Abrahamson N, Addo K (2010) Ground-motion attenuation model for small-to-moderate shallow crustal earthquakes in California and its implications on regionalization of ground-motion prediction models. Earthq Spectra 26:907-926

Douglas J (2004) An investigation of analysis of variance as a tool for exploring regional differences in strong ground motions. J Seismol 8:485-496 
Douglas J (2007) On the regional dependence of earthquake response spectra. ISET J Earthq Technol 44(1):71-99

Douglas J (2010) Assessing the epistemic uncertainty of ground-motion predictions. In: Proceedings of the ninth US National and 10th Canadian conference on earthquake engineering, July 25-29, Toronto, Ontario, Canada

Douglas J (2011) Ground-motion prediction equations 1964-2010. PEER 2011/102

Douglas J, Akkar S, Ameri G, Bard P-Y, Bindi D, Bommer JJ, Bora SS, Cotton F, Derras B, Hermkes M, Kuehn NM, Luzi L, Massa M, Pacor F, Riggelsen C, Sandikkaya MA, Scherbaum F, Stafford PJ, Traversa P (2014) Comparisons among the five ground-motion models 1 developed using RESORCE for the prediction of response spectral accelerations due to earthquakes in Europe and the Middle East. Bull Earthq Eng 12(1):341-358

Esteva L, Rosenblueth E (1964) Espectros de temblores a distancias moderadas y grandes. Boletin Sociedad Mexicana de Ingenieria Sesmica 2:1-18, In Spanish

Gregor N, Abrahamson NA, Atkinson GM, Boore DM, Bozorgnia Y, Campbell KW, Chiou BS-J, Idriss IM, Kamai R, Seyhan E, Silva W, Stewart JP, Youngs R (2014) Comparison of NGA-West2 GMPEs. Earthq Spectra 30(3):1179-1197

Kaklamanos J, Baise LG (2011) Model validations and comparisons of the next generation attenuation of ground motions (NGA-West) project. Bull Seismol Soc Am 101:160-175

Kale Ö, Akkar S, Ansari A, Hamzehloo H (2015) A ground-motion predictive model for Iran and Turkey for horizontal PGA, PGV and 5\%-damped response spectrum: investigation of possible regional effects. Bull Seismol Soc Am (Submitted)

Luzi L, Hailemikael S, Bindi D, Pacor F, Mele F, Sabetta F (2008) ITACA (ITalian ACcelerometric Archive): a web portal for the dissemination of the Italian strong motion data. Seismol Res Lett 79:716-722

Massa M, Morasca P, Moratto L, Marzorati S, Costa G, Spallarossa D (2008) Empirical groundmotion prediction equations for northern Italy using weak- and strong-motion amplitudes, frequency content, and duration parameters. Bull Seismol Soc Am 98(3):1319-1342

Power M, Chiou B, Abrahamson N, Bozorgnia Y, Shantz T, Roblee C (2008) An overview of the NGA project. Earthq Spectra 24:3-21

Sabetta F, Pugliese A (1996) Estimation of response spectra and simulation of nonstationary earthquake ground motions. Bull Seismol Soc Am 86(2):337-352

Sandıkkaya MA, Akkar S (2013) Reference database for seismic ground-motion in Europe (version 2). EERC-METU, Ankara

Sandıkkaya MA, Yılmaz MT, Bakır BS, Yılmaz Ö (2010) Site classification of Turkish national strong-motion stations. J Seismol 14:543-563

Scasserra G, Stewart JP, Bazzurro P, Lanzo G, Mollaioli F (2009) A comparison of NGA groundmotion prediction equations to Italian data. Bull Seismol Soc Am 99:2961-2978

Strasser FO, Abrahamson NA, Bommer JJ (2009) Sigma: issues, insights, and challenges. Seismol Res Lett 80(1):40-56

Theodulidis N, Kalogeras I, Papazachos C, Karastathis V, Margaris B, Papaioannou C, Skarlatoudis A (2004) HEAD 1.0: a unified HEllenic accelerogram database. Seismol Res Lett 75:36-45

Traversa P, Akkar S, Ameri G, Cotton F, Douglas J, Frobert L, Godey S, Hernandez B, Luzi L, Sandikkaya MA (2014) REference databaSe fOR seismiC groundmotion in Europe. Second European conference on earthquake engineering and seismology, İstanbul

Tromans IJ, Bommer JJ (2002) The attenuation of strong-motion peaks in Europe. In: Proceedings of twelfth European conference on earthquake engineering, Paper no.394

Yenier E, Atkinson G (2014) Equivalent point-source modeling of moderate-to-large magnitude earthquakes and associated ground-motion saturation effects. Bull Seismol Soc Am 104(3):1458-1478

Yenier E, Sandikkaya MA, Akkar S (2010) Report on the fundamental features of the extended strong motion databank prepared for the SHARE project. Deliverable 4.1 of seventh framework programme project seismic hazard harmonization in Europe (SHARE), 34 pages, Ankara, p 44 